\title{
Combustor Development and Performance Analysis for Recuperated Microturbine Application
}

\author{
Yize Liu ${ }^{1}$, Theoklis Nikolaidis, ${ }^{2}$ Abdelaziz Gamil ${ }^{3}$ \\ 1, 2, 3 Cranfield University, Cranfield, Bedfordshire, MK43 OAL, United Kingdom
}

\author{
Seyed Hossein Madani, ${ }^{4}$ Mohammad Sarkandi ${ }^{5}$ \\ 4, 5 Samad Power Ltd, Milton Keynes, Buckinghamshire, MK11 3JB, United Kingdom
}

\begin{abstract}
In recent years, increased attention is paid to the microturbine MGT as a promising technology for combined heat and power (CHP) applications. An MGT has advantages of high reliability, high efficiency, lower manufacturing and maintenance costs, reduced vibration and noise levels, and clean emissions. Recuperation can further increase efficiency by recycling the heat from the turbine exhaust and preheating the air for combustion via a heat exchanger. Such a system will be realized by designing a combustion chamber that can meet various design and operability requirements. This paper presents an overview of the combustor development and provides CFD analysis on combustor performance and emissions. A single tubular combustor is designed, and the direct injection mode is applied to mitigate the autoignition and flashback risks resulting from the high preheating temperature. Heat transfer and cooling analysis indicate that ceramic liner is capable of tolerating high temperature using effusion cooling. Studies of flow characteristics, temperature field, pressure loss, and pattern factor are provided in detail. The effects of design parameters and methods (i.e., fuel-air mixture strength, cooling hole angles, dilution hole design approaches) are also discussed. Finally, the use of biomass is investigated and shows that it has the potential to achieve a high combustion efficiency and low emissions for the recuperated microturbine application.
\end{abstract}

I. Nomenclature

$\begin{array}{ll}C F D & =\text { Computational Fluid Dynamics } \\ C H P & =\text { Combined Heat and Power } \\ C R Z & =\text { Corner Recirculation Zone } \\ I & =\text { Intensity factor } \\ L H V & =\text { Lower Heating Value } \\ M R Z & =\text { Main Recirculation Zone } \\ P_{3} & =\text { combustor inlet pressure } \\ P F & =\text { Pattern Factor } \\ q_{\text {cond }} & =\text { conduction heat } \\ q_{\text {cov_h }} & =\text { convection heat inside the cooling hole } \\ q_{\text {cov_l }} & =\text { convection heat to liner } \\ q_{\text {rad }} & =\text { radiation heat } \\ T_{\text {in }} & =\text { combustor inlet temperature } \\ T_{\text {max }} & =\text { maximum temperature } \\ T_{\text {out }} & =\text { combustor outlet temperature } \\ V_{C} & =\text { combustor volume } \\ W_{3} & =\text { combustor inlet air mass flow }\end{array}$

\footnotetext{
${ }^{1}$ Research fellow in gas turbine combustor design at Cranfield University. yize99@outlook.com

${ }^{2}$ Reader in gas turbine performance and numerical simulation at Cranfield University

${ }^{3}$ Research fellow in micro gas turbine performance at Cranfield University

${ }^{4}$ Head of research and development at Samad Power, Ltd.

5 Engineering manager at Samad Power, Ltd.
} 


\section{Introduction}

Stationary microturbines provide a reliable, fuel-flexible, efficient, and cost-effective power source for combined heat and power (CHP) production. [1-3] Recuperation can further increase efficiency by recycling the heat from the turbine exhaust and preheating the air for combustion via a heat exchanger. [4] The flexibility and adaptability of the proposed system will be achieved by designing a combustion chamber for the micro gas turbine that can operate efficiently.

The design of a micro gas turbine combustor is a challenging task: the combustor has a small volume to meet all the design and operational requirements such as high combustion efficiency, high fuel flexibility, high flame stability, high liner durability, low emission, and low noise levels. Furthermore, it demands knowledge of complex turbulent flow, fuel-air mixing, detailed chemical kinetics, mechanical integrity, etc. Several micro gas turbine combustor designs are evolved over the last few decades: 1) Swirl-stabilized flame combustors: the flame is sustained using air swirlers [5-7] 2) Jet-stabilized flame combustors: It is based on exhaust gas recirculation and the flame is Jet-stabilized. Exhaust gas is used to cool the flame and suppress thermal [8,9] NOx. 3) Vaporization tubes combustors: it is divided into small tubes where fuel is injected. Fuel is atomized, mixed with air, and vaporized by contacting with hot temperature surface inside the tube walls $[10,11] 4)$ staged flame combustors [12]: fuel stating is implemented to improve the MGT operability. The pilot stage is working at low power for stable combustion and the main stage operates at high power for emission controls.

Recuperated microturbine combustors are designed to be used in the residential sector. [13] A micro-CHP system was developed with a counter-flow heat exchanger used as a recuperator. A flameless combustor firing natural gas is designed based on numerical modeling. Preliminary testing indicates that low NOx and CO emissions are achieved. Recuperated microturbine combustors have also been developed for a miniature aircraft engine. [14] Preliminary design is developed to meet different design and operational requirements. Also, rig testing is performed to investigate the flow aerodynamics, ignition, and flame dynamics.

Less availability of fossil fuels and continuous demands for electricity and energy supplies lead to the development of a microturbine system with renewable energy. Biofuels are derived from microbial, plant, or animal materials. Research interest in MGT operating biofuels increases rapidly in recent years. [15,16] Analysis shows that biofuels produce less emissions compared to conventional fuels such as natural gas and diesel. Some typical challenges for operating biofuels are also reported in Ref. [17-19]. For example, biodiesels have lower oxidation stability and are more corrosive than conventional diesel. Thus, the fuel storage temperature, the use of antioxidants, the optimized fuel filtering system, the selection of materials, the careful design of the atomizer and combustion chamber, etc. are considered to enable fuel adaptation to the MGT system.

This paper presents an overview of the combustor development and provides an analysis of combustor performance and emission characteristics. The microturbine under development is initially described. The combustor development and design are provided. Heat transfer analysis is presented and shows that ceramic liner with effusion cooling is capable to cool the liner. Performance analysis (i.e., flow characteristics, pressure drop, emission, and pattern factor) on the baseline design using the CFD approach are provided. The effect of design parameters on combustor performance is studied. In particular, the effect of fuel-air mixture strength on temperature and emissions, the effect of cooling hole injection angle on heat transfer and liner temperature, and the effect of design method on dilution hole performance, are explored. Finally, the potential operation of biomass is investigated and shows that the biomass has potential towards a high combustion efficiency, high reliability, a low-pressure loss, and low emissions.

\section{Microturbine}

The micro gas turbine is a reliable and well-proven technology with only one moving part. Turbo Green burner (TGB, Samad Power Ltd.) is working based on the Brayton cycle including an air compressor, turbine, combustor, recuperator, heat exchanger, and a motor/generator, generates up to $3 \mathrm{~kW}$ of electricity and $25 \mathrm{~kW}$ of heat simultaneously.

The schematic representation of the microturbine layout is presented in Fig. 1. Air from outside the building will be sucked into the air compressor. Fuel and compressed air will be mixed and burnt inside the combustion chamber in a constant pressure process. Hot burned gas will be expanded inside the turbine which would convert the energy to shaft torsional power and resultant shaft work will be used to generate power inside the Generator. To increase the efficiency of the cycle, the turbine exhaust heat will be transferred to the recuperator to heat the air from the compressor before the air enters the combustion chamber. 


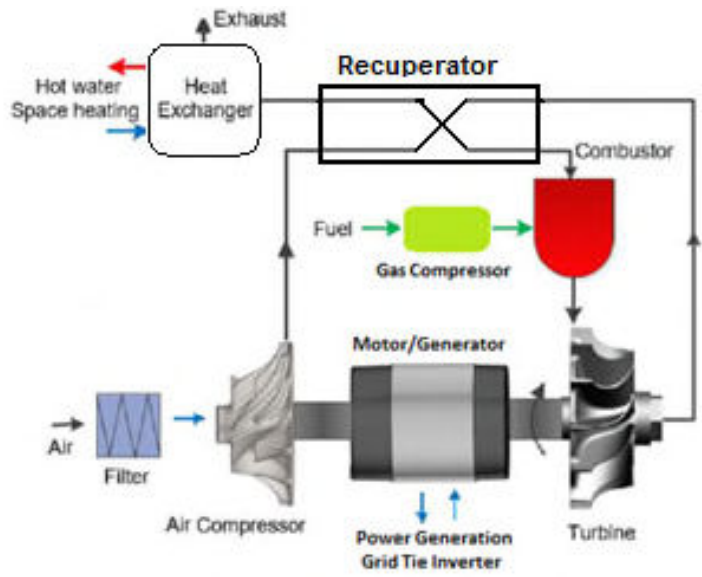

Figure1. Microturbine layout

\section{Combustor development}

The combustor is expected to be integrated into the microturbine, TGB shown in section III. The aerothermal design data are defined before the combustor development. The main thermodynamic parameters are listed in Table 1. The combustor operates at around 3 bars, with an air mass flow of $0.075 \mathrm{~kg} / \mathrm{s}$. The combustor inlet temperature reaches $1000 \mathrm{k}$. The turbine inlet temperature is set to be $1200 \mathrm{~K}$. LPG (i.e., $60 \% \mathrm{C}_{3} \mathrm{H}_{8}$ and $40 \%$ $\mathrm{C}_{4} \mathrm{H}_{10}[20]$ ) is used as the initial fuel type. The fuel flow rate is determined based on the LHV and temperature rise in the combustor.

For the combustor layout definition, a single-tubular type combustor is selected for development based on ease of manufacturing, simple thermal management for fuel injectors, ease of access of components, and geometric flexibility. Direct injection mode is implemented to eliminate the autoignition and flashback issues resulting from the high preheating temperature. Fuel characteristics are explored before the injector design. The property for LPG is reported in Table 2. The developed fuel nozzle features a multi-point injection that allows a more uniform fuel-air mixing in the primary zone. The combustor operates a lean-combustion mode to achieve low pollutants. A radial-type swirler is fitted at the injector head to achieve swirl-stabilized combustion inside the combustor chamber. A casing that surrounds the liner is installed to enable the staging of the zonal jets through the designed liner holes. For ignition, a spark plug is located near the primary zone to achieve ignition.

$$
\begin{gathered}
\Lambda=\frac{W_{3}}{V c P_{3}^{1.8} 10^{0.00145\left(T_{3}-400\right)}} \quad \text { (Eq. 1) } \\
I=\frac{W_{f} \eta L H V}{V c P_{3}} \quad \text { (Eq. 2) } \\
\left.P F=\frac{T_{\text {max }}-T_{\text {out }}}{T_{\text {out }}-T_{\text {in }}} \quad \text { (Eq. } 3\right)
\end{gathered}
$$

Figure 2 shows the schematic representation of the developed combustor. The airflow splits between each component are calculated. In this case, air fractions through the swirler, cooling, dilution holes are estimated. The fuel-air stoichiometry within each combustor zone is then defined. The primary task for designing the combustion chamber is to define the overall dimension of the liner. The liner geometry is derived based on empirical factors. (Eq. 1,2) [21-23] A truncated convergent cone is added downstream of the liner to connect the turbine inlet section. For air swirler design, a radial type swirler is used. Flat vanes are installed circumferentially around the plate with equal spacing. Iterations of geometrical variables (i.e. vane angles, spacing, number) are performed until a sufficient swirl number is achieved. The dimensions for the fuel nozzle orifice are calculated based on the estimated fuel mass flow and pressure drop. The dilution hole diameter and number are designed to allow sufficient jet penetration and achievement of lower pattern factor (Eq.3)

Table 1. Thermodynamic design parameter

\begin{tabular}{|l|l|}
\hline Parameter & Values \\
\hline Air inlet total temperature K & 1000 \\
\hline Air inlet total pressure bar & 3 \\
\hline Air inlet mass flow kg/s & 0.075 \\
\hline Turbine inlet temperature K & 1200 \\
\hline Initial fuel type & LPG \\
\hline
\end{tabular}


Table 2. Physical and chemical properties of LPG

\begin{tabular}{|l|l|}
\hline Property & Values \\
\hline Chemical name/formula & $\begin{array}{l}\text { C3H8/C4H10 } \\
(60 \% \text { C3H8 40\% C4H10) }\end{array}$ \\
\hline Flammability in air (\%) & $2.2-9.5[24]$ \\
\hline Auto ignition temperature K & $723[24]$ \\
\hline Density $\left(\mathrm{kg} / \mathrm{m}^{3}\right)$ at $288 \mathrm{~K}$ & $1.898[25]$ \\
\hline Lower Heating Value LHV, MJ/kg & $45.4[25]$ \\
\hline Flash point, K & $169[25]$ \\
\hline Freezing point, $\mathrm{K}$ & $85[25]$ \\
\hline
\end{tabular}
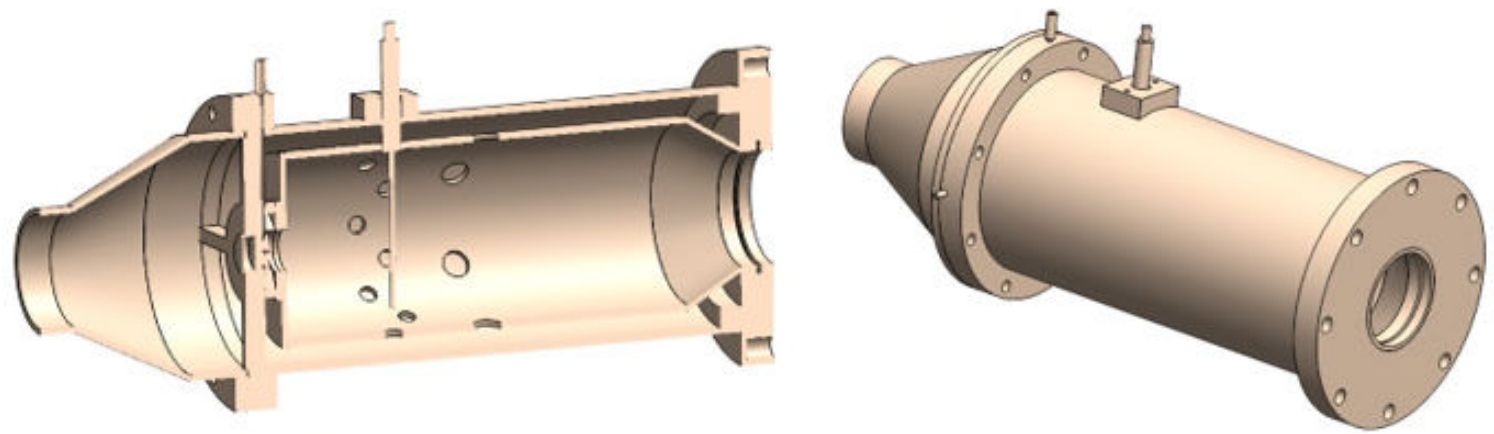

Figure 2. The schematic drawing of the developed combustor

\section{Liner cooling analysis}

For recuperated microturbines, the high temperature of preheated air is less effective to cool the liner and hence results in a liner durability challenge for normal metal alloys. In this study, the ceramic liner with effusion cooling type is studied. (Fig.4) Heat transfer cooling analysis is performed by following the procedure shown in Fig.3. Combustor thermodynamic parameters are required to initialize the analysis. In this case, the combustor inlet mass flow, pressure, temperature, fuel-air stochiometric distribution in each zone. The liner and cooling geometries are obtained from the combustor design model. The geometric data are used to define the computational domain and provide the basis for the liner cooling calculations. The cooling system is discretized using the finite difference method and nodal points are established in a 2-dimensional layout. In this case, the axial and radial directions of the liner are considered. The averaged property in the circumferential direction is computed. Then, the zonal flame temperature calculations are performed based on the predetermined zonal fuelair stoichiometry. The algorithm used is based on the enthalpy balance taking account of the dissociation effect. [26] Based on the available temperature data, the thermodynamic properties of the coolant and gas are calculated. In particular, the heat conductivity, heat capacity, density, and viscosity. Heat transfer calculations are subsequently conducted with radiation, convection, and conduction took as the main mechanism. For effusion cooling, the heat transfer inside the effusion holes is also taken into account. The criterion for determining the correct liner nodal temperatures is to solve the heat balance on each node. (Eq.4) The nodal temperatures at the outer liner surface are of main interest. Iterations of geometrical parameters are required if the calculated temperatures exceed the material temperature limits.

$$
q_{\text {rad }}+q_{\text {cov } \_}-q_{\text {cov }_{h}}-q_{\text {cond }}=0
$$

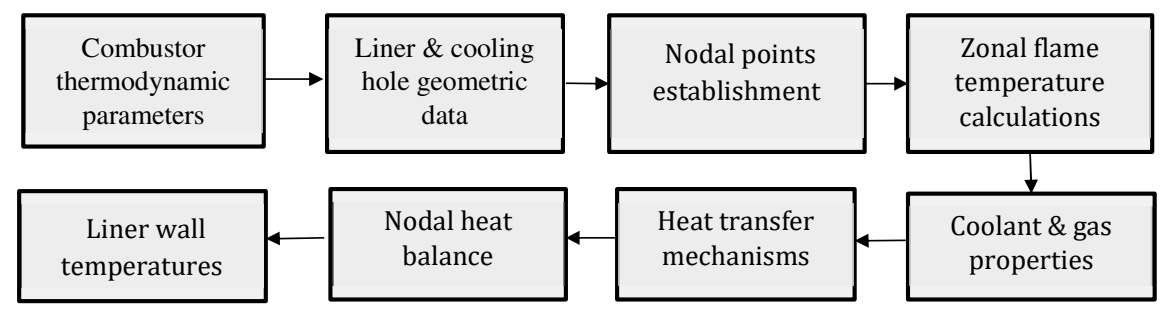

Figure 3. Liner heat transfer and cooling analysis procedure 
The preliminary heat transfer analysis shows that the ceramic liner is capable of tolerating high temperatures using effusion cooling. The liner axial nodal temperatures are computed at different air inlet temperatures (Fig. 5) Results show that all of the nodal temperatures are below the temperature limit with a margin of hundreds of kelvins. The temperature rise in the combustor, as well as thermal gradients across the liner wall, are not as high as in non-recuperated microturbines, the single-wall ceramic liner with effusion cooling is sufficient to withstand the thermal loading. Therefore, this cooling type will be considered for further development.

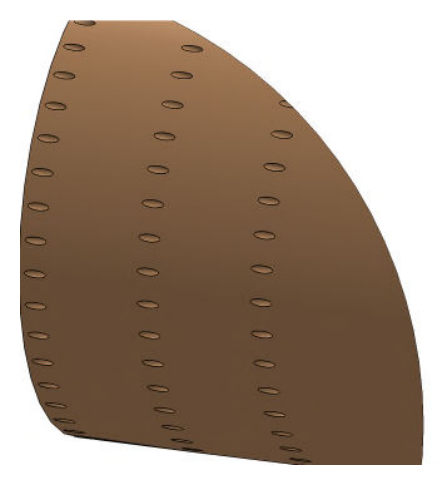

Figure 4. Effusion cooling layout

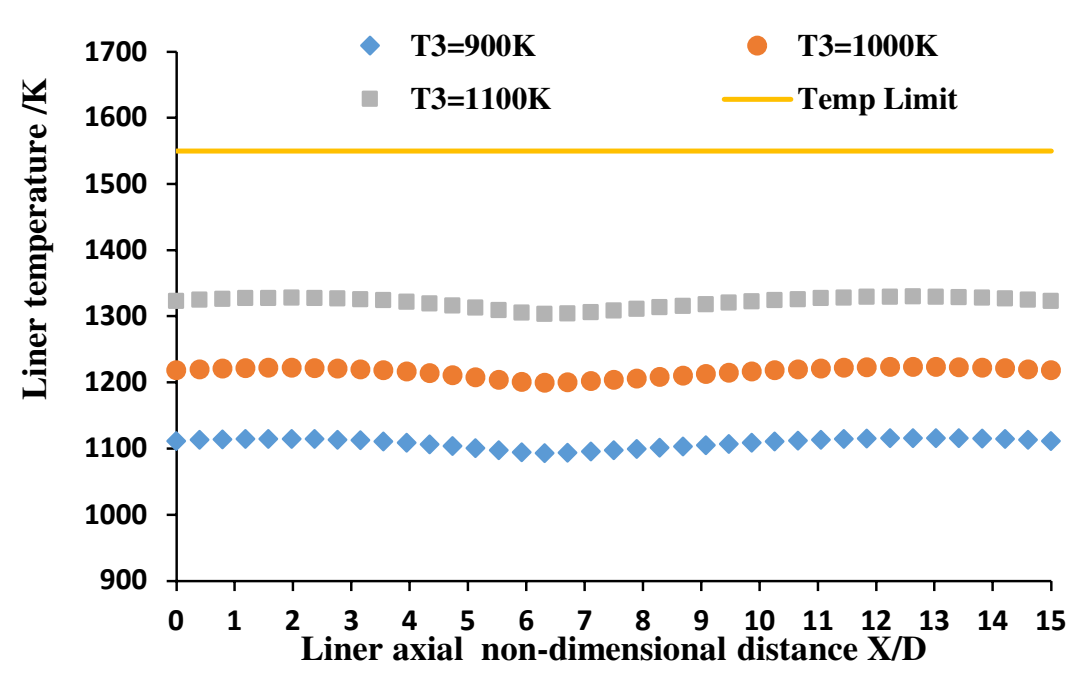

Figure 5. Outer Liner surface axial nodal temperatures at different combustor inlet temperatures

\section{CFD analysis}

The commercial code ANSYS Fluent 19.1 is used to simulate the combustor performance. [27], [28] The CAD model is converted to the fluid domain. The hybrid grids containing hexahedra and tetrahedral elements are generated considering the geometry is relatively complex. The total mesh element is 10 million. The 3-D computational domain is defined by applying different boundary conditions. (Fig.6 only shows a 2-D plane) Mass flow rates are imposed at the combustor inlet and fuel injection orifices. Pressure is defined at the combustor outlet plane. For combustor component surfaces, the no-slip stationary wall conditions are applied. The 2-equation model is used for turbulence modeling. For non-reacting flow simulations, the SIMPLE algorithm for pressurevelocity coupling is chosen as the solver. For combustion modeling, Flamelet Generated Manifold (FGM) approach is utilized to model turbulence-chemistry interaction. [29] The coupled pressure-velocity scheme is selected as the solver. Emission calculations are also considered during the combustion simulations. Thermal and prompt formations are taken into account when modeling NOx emissions. [30], [31]

The 3-D CFD analysis is performed on the designed combustor. The flow structure inside the combustion chamber is initially investigated. The non-reacting flow streamlines are presented along the combustor mid-plane, 
as indicated in Fig. 7. The recirculation flows are formed at the primary zone. These are achieved via the combination of the designed radial swirler and primary mixing jet. For the reacting flow case (Fig.8), the main center recirculation zones MRZ are also established at the dome front. The radial flow velocity is increased due to gas expansion during the combustion process. The high radial flow jets established corner recirculation zone CRZ. The center and secondary recirculation flow help to stabilize the flame and sustain the combustion by entraining the hot gases and providing continuous ignition to the incoming fuel-air mixture. For both non-reacting and reacting flow simulations, high local jet velocities are formed at air mixing jet holes to provide sufficient jet penetration. Downstream of the combustor dome, the adverse pressure gradient along the axial direction is greatly reduced with the high axial flow towards the combustor outlet.

The temperature field is depicted in Fig.8. The averaged gas temperature in the primary zone is $1650 \mathrm{~K}$, a peak temperature of $1801 \mathrm{~K}$ is noticed at the center of the dome front end. Downstream of the primary zone, the hot gas mixes with the dilution jets. A more uniform temperature is formed with its value goes down to $1200 \mathrm{~K}$ at the combustor outlet plane to drive the turbine. The pressure calculations are also performed. The overall pressure drop is calculated based on the total pressure differentials between the inlet and outlet of the combustor. The cold pressure loss is $2.7 \%$. For the reacting flow case, the overall pressure drop is $3.4 \%$ and the resulting hot loss is $0.7 \%$.

The NOx concentration map (Fig.9) shows that NOx species are formed primarily at the high-temperature reaction zone. This indicates NOx emission has a strong dependency on temperature, which agrees with the theory.[32] Downstream of the combustion chamber, the air staging process controls the peak temperature so at the low NOx mass fraction of $1.5 \times 10^{-6}$ produced at the outlet. Fig 10. presents CO emission contour plot along the combustor mid-plane. The majority of $\mathrm{CO}$ species are initially formed near the fuel nozzle tip region, the high reaction temperature promotes $\mathrm{CO}$ to $\mathrm{CO}_{2}$ conversion process. Moreover, the $\mathrm{CO}$ concentration is further diluted by the dilution air and at the outlet is the mass fraction is $1.9 \times 10^{-5}$. Meanwhile, the pattern factor is calculated based on Eq 3. The area-weighted averaged temperature at the combustor outlet plane is taken as outlet temperature $T_{\text {out }}$. The facet maximum value at the same plane is extracted as the maximum temperature $T_{\text {max }}$. The predicted pattern factor is 0.1 . The resulting combustion efficiency reaches over $99 \%$.

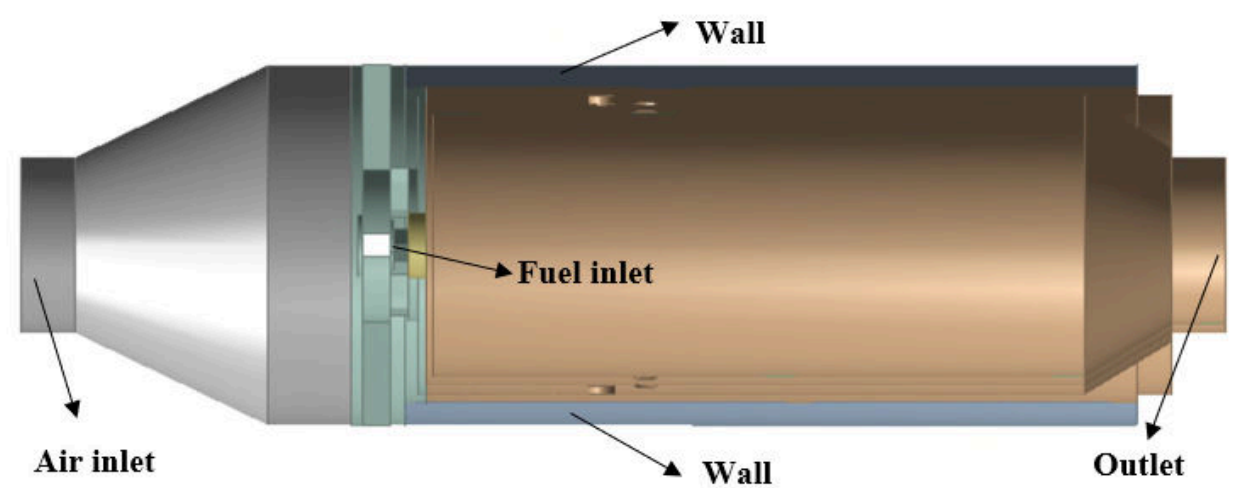

Figure 6. Computational domain (3-D but only shows 2-D)

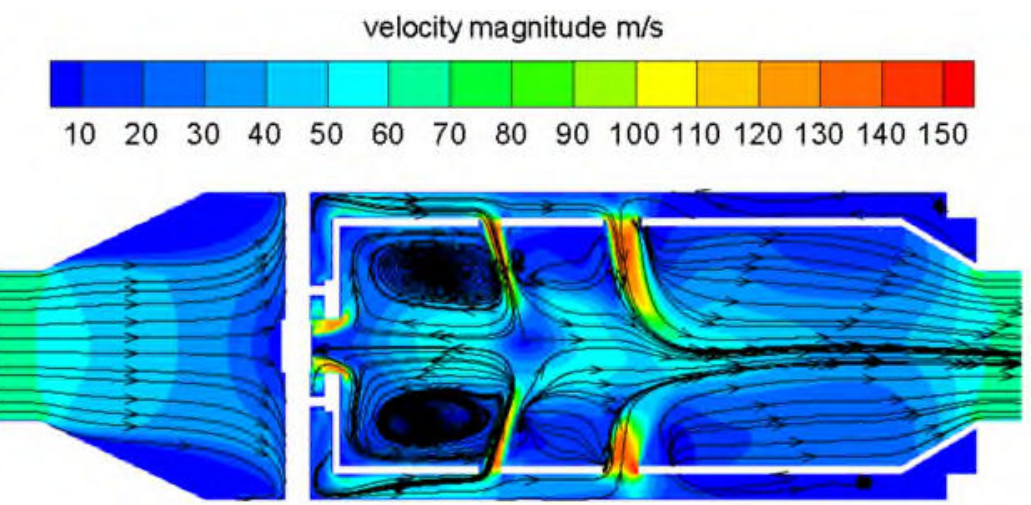

Figure 7. Non-reacting flow velocity field with streamlines 


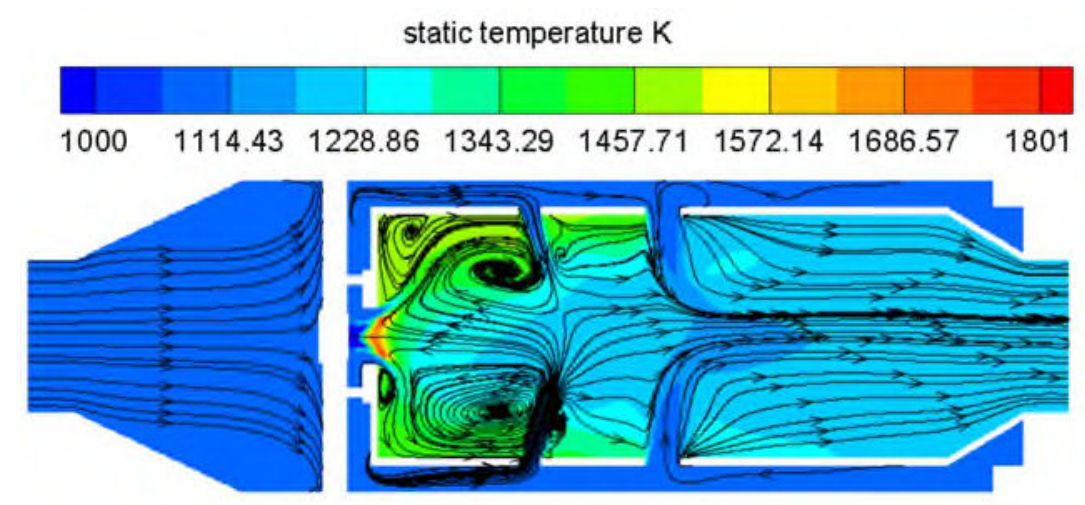

Figure 8. Reacting flow temperature field with flow streamlines

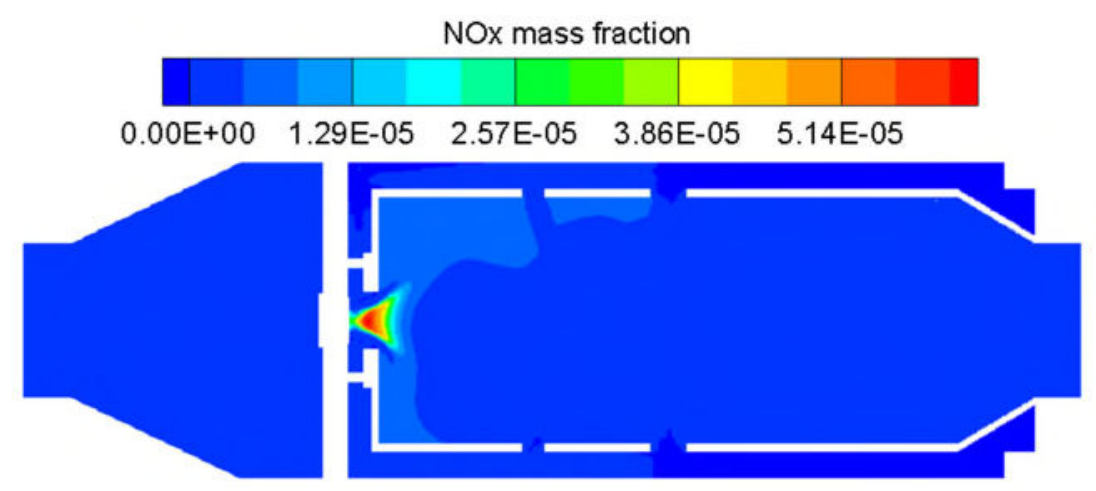

Figure 9. Nox mass concentration

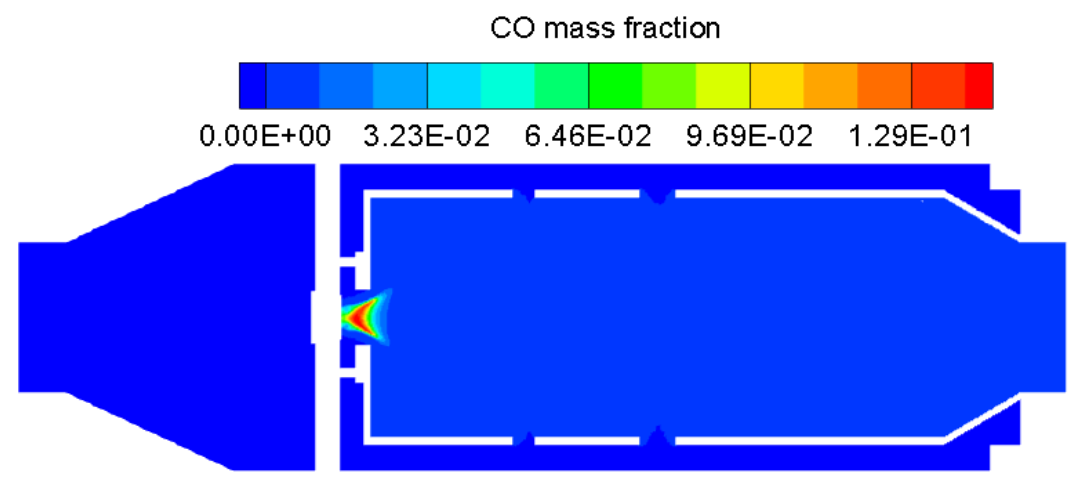

Figure 10. CO mass concentration

\section{Effects of design parameters, methods, and fuels on performance}

\section{Effect of reaction zone fuel-air mixture}

The high temperature of the preheated reactant enables the combustion to operate with wider fuel flammability limits. Temperatures and NOx emissions are computed at various equivalence ratios in the range of 0.4-0.7. For temperature calculations, the volumetric averaged temperatures in the reaction zone are determined. For NOx calculations, the mass fractions at the combustor outlet are obtained. The results are reported in Table 3. At an equivalence ratio of 0.7 , the reaction zone temperature is $2131 \mathrm{~K}$. The resulting NOx level is $3.9 \times 10^{-5}$. At an equivalence ratio of 0.6 , the reaction zone temperature reaches $1890 \mathrm{~K}$. The overall NOx production at the combustor outlet plane is calculated to be $1.2 \times 10^{-5}$. When the combustor operates at an equivalence ratio of 0.5 . A moderate averaged temperature of $1650 \mathrm{~K}$ occurs. The total computed level reduces to $1 / 4$ of the level at an equivalence ratio of 0.6. Simulations indicate that the NOx production in particular the thermal NO is strongly 
influenced by the reaction temperature. It shows that reaction zonal fuel-air mixture has a significant impact on NOx production and the potential of achieving a very low level of NOx at a leaner condition. An even lower equivalence ratio of 0.4 is also simulated with the lowest NOx of $0.3 \times 10^{-6}$ obtained. All case studies are performed at the design point. To ensure the flame stability at a wide range of engine operating conditions, simulations are also conducted at off-designs (i.e., low powers.) For each case, the mass flow fraction remains similar at both design and off-designs. It is noticed that when an equivalence ratio of 0.4 is set at the design point, the flame instability issue occurs at lower power, and combustion is not sustained even though a patched ignition temperature of $2100 \mathrm{~K}$ is imposed during simulations. The current design aims to avoid the extra system complexity and cost, the staged combustion process is not applicable in this design. Therefore, a trade-off between the sufficient reaction temperature to sustain the combustion and the maximum allowable NOx level is considered by determining the optimal reaction zone fuel-air mixture strength.

Table 3. Temperature and NOx at various fuel-air mixture strength

\begin{tabular}{|l|l|l|}
\hline Fuel-air mixture strength & Reaction zone averaged temperature $\mathbf{T}$ & NOx mass fraction \\
\hline 0.4 & 1424 & $0.3 \times 10^{-6}$ \\
\hline 0.5 & 1650 & $1.5 \times 10^{-6}$ \\
\hline 0.6 & 1890 & $1.2 \times 10^{-5}$ \\
\hline 0.7 & 2131 & $3.9 \times 10^{-5}$ \\
\hline
\end{tabular}

Effect of effusion injection angle

The effusion cooling implements an angled injection mode. The analysis aims to investigate the effect of the hole angle on cooling performance by assessing liner wall temperatures. Fig. 11 shows the effusion hole angle in 2 -D layout. The averaged and maximum nodal temperatures are computed at the inlet air temperature of $1000 \mathrm{~K}$ using the approach described in section V. The results are reported in Fig. 12 and show that a smaller injection hole overall presents an enhanced cooling performance, in particular, the achievement of lowest averaged and peak wall temperatures. However, for the high temperature of preheating air, a less- effective reduction in liner temperature is noticed for shallow angles compared to steep angles, with a difference of $10-20 \mathrm{~K}$. Considering the shallow angles present manufacturing and mechanical integrity challenges, a moderate injection angle will be sufficient to cool the current liner in this design.

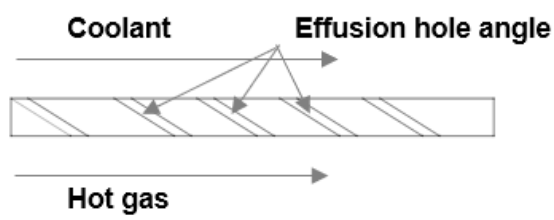

Figure 11. The schematic drawing showing the 2D effusion hole layout and angle

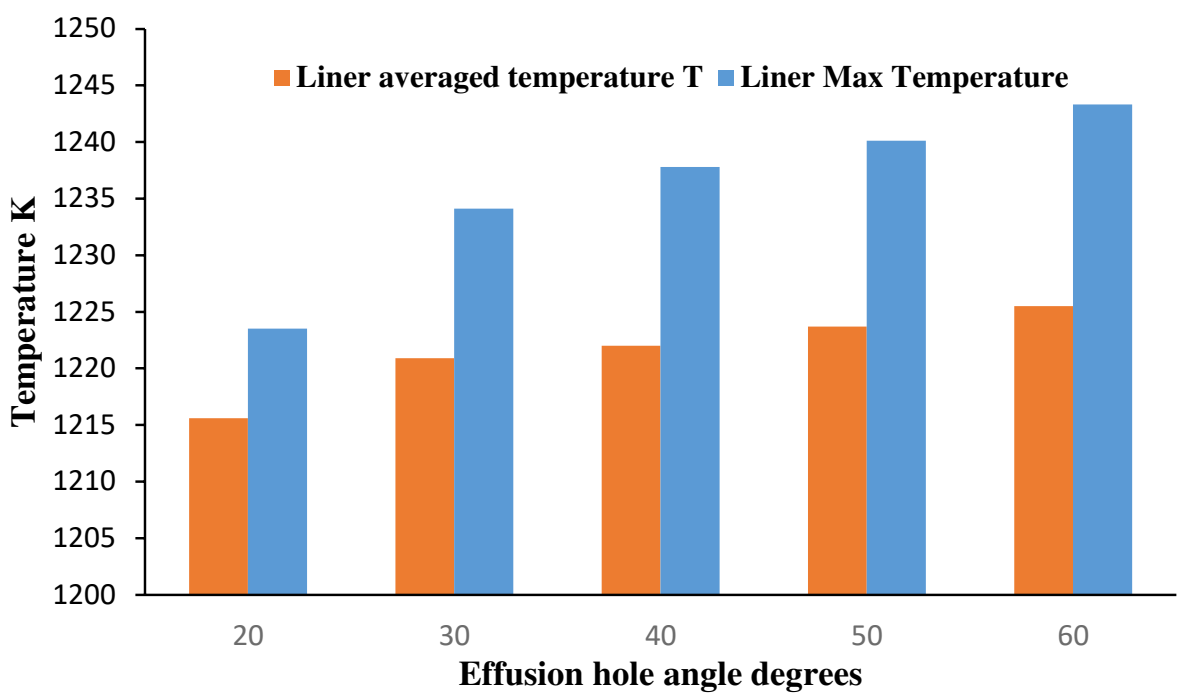

Figure 12. Averaged and maximum liner temperatures at different effusion hole angles 


\section{Effect of dilution hole design method}

The current dilution holes are designed using the classic design approach called the 'Cranfield Design Method'.[21] There is another well-known approach, 'NASA Design Method' that developed by Holdeman et al. [33] The main difference between the two approaches lies in the focus on the design parameters. The former method initially determines the hole diameter and spacing is derived based on total area whilst the latter approach focuses on defining the optimum numbers of the hole. The resulting hole dimensions are different using two approaches. In this case, Cranfield Design Method yields larger numbers of dilution holes, but a smaller hole diameter compared to those derived by NASA Design Method. Thus, there is an interest to investigate the effect of different methods on performance in terms of pattern factor and TIT. Simulations are performed on both dilution hole configurations and the same CFD models and boundary conditions are applied. Results are reported in Table 4. Both hole designs yield similar results for pattern factors. The simulation with hole configuration A results in a slightly higher TIT, which is beneficial for MGT cycle efficiency. Overall, for the current recuperated application, there is a minor difference in dilution hole performance using the two methods.

Table 4. Effect of dilution hole design methods on pattern factor and TIT

\begin{tabular}{|l|l|l|l|}
\hline Hole configuration & Design method & Pattern factor & TIT \\
\hline A & Cranfield Design Method & 0.10 & 1192.1 \\
\hline B & NASA Design Method & 0.11 & 1187.6 \\
\hline
\end{tabular}

\section{Effect of biomass}

The designed combustor is considered to be fuel flexible. In addition, the preheating combustor inlet air enables the combustion of lower LHV fuels. Therefore, a growing interest to investigate biomass in this research. CFD analysis is performed on the same combustor design feeding with biomass. The LHV of the biomass is 9.40 $\mathrm{MJ} / \mathrm{kg}$. [34] The fuel species and volume fractions are listed in Table 5. For comparisons, temperature fields with flow streamlines are presented in Fig.13, for LPG and Biogas. The scale for temperature is set to be a nondimensional format with temperatures for LPG taken as the reference. It can be noted that the combustor feeding with biogas produces lower temperatures, both in terms of peak flame temperature and averaged reaction zone temperature. To investigate the flow characteristics, the reacting flow velocity streamlines are also presented. The flow structures for both cases are similar: the main recirculation zones MRZ are formed in the primary zone, and corner recirculation zones CRZ are also noticed. The size for CRZ is much smaller compared to that for MRZ. Performance and emission analyses are also conducted. Results are summarized in Fig.14. LPG produces a higher flame temperature. The combustion efficiency levels for both fuels reach up to $99.9 \%$. The combustor also maintains similar pressure loss and pattern factor levels: $3.4 \%$ for LPG and 3.3\% for biogas. 0.1 for LPG and 0.12 for biogas. From emissions perspectives, simulations indicate that by running the biogas the current combustion chamber has the potential to achieve lower NOx and CO emissions: an 84\% of reduction in NOx and a $60 \%$ of reduction in $\mathrm{CO}$ can be attained compared to the cases operating with LPG.

Table 5. Fuel composition of the biogas [34]

\begin{tabular}{|l|l|}
\hline Fuel composition & Volume fraction \\
\hline $\mathrm{H}_{2}$ & $7 \%$ \\
\hline $\mathrm{CO}$ & $29 \%$ \\
\hline $\mathrm{CH}_{4}$ & $21 \%$ \\
\hline $\mathrm{CO}_{2}$ & $38 \%$ \\
\hline $\mathrm{H}_{2} \mathrm{O}$ & $5 \%$ \\
\hline
\end{tabular}




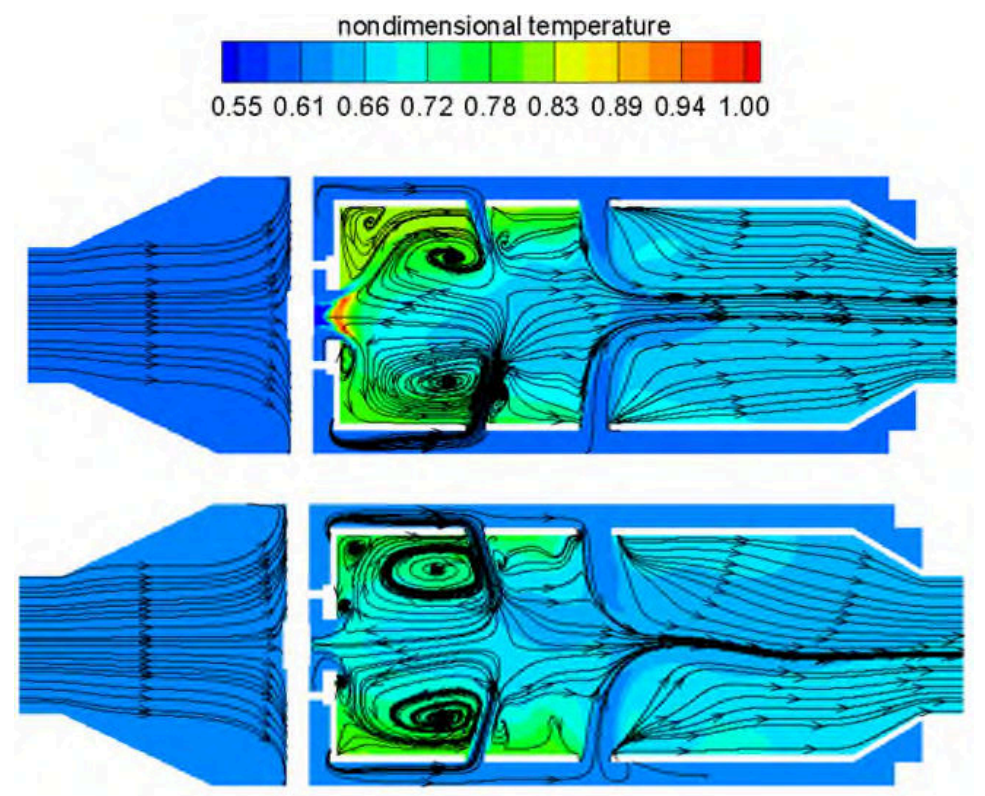

Figure 13. Temperature field with streamlines for LPG (top) and Biogas (bottom)
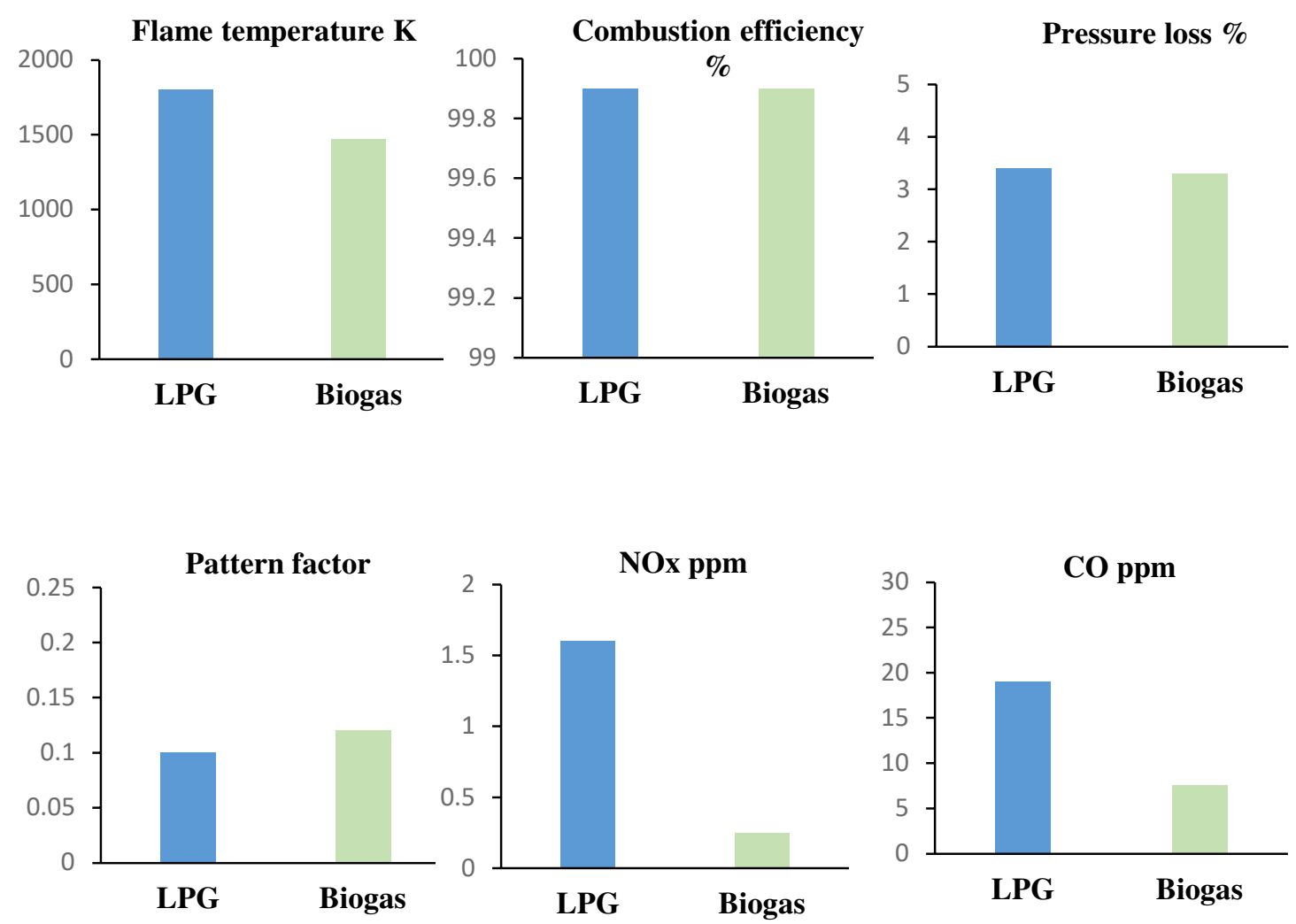

Figure 14. Performance and emissions for LPG and Biogas

\section{VIII.Conclusions}

In this paper, a combustor is developed for a recuperated microturbine application that generates up to $3 \mathrm{~kW}$ of electricity and $25 \mathrm{~kW}$ of heat simultaneously. Direct injection mode is implemented to mitigate the autoignition and flashback risks resulting from the high preheating temperature. The high temperature of preheated air is less effective to cool the liner and hence results in a liner durability challenge. Heat transfer analysis shows that 
utilizing the effusion cooling with a ceramic liner can effectively withstand the thermal load. Numerical analysis is subsequently performed on the designed combustor using the CFD approach. The flow characteristics for both non-reacting and reacting flow are investigated. Furthermore, the temperature, pressure loss, combustion efficiency, pattern factor, NOx, and CO emissions are also analyzed. The effects of design parameters, method, and fuel are then studied. Reaction zone fuel-air mixture has a significant impact on NOx production and the potential of achieving a very low level of NOx at a leaner condition. However, in such a condition, the flame instability issue is noticed at lower powers. Thus, a moderate value is considered to sustain combustion. A shallow effusion cooling hole angle results in lower liner temperatures. However, based on the manufacturing challenge and liner integrity considerations, a moderate angle would be sufficient to tolerate the thermal load. The effect of different dilution hole design methods is examined. Two design methods produce different hole configurations. Overall, for the current recuperated application, there is a minor difference in dilution hole performance using the two methods. Pattern factor and TIT are compared and indicate that similar results are obtained for both designs. A slightly higher TIT is obtained using the 'Cranfield Design Method'. Finally, the potential operation of biomass is investigated. The flow structure is similar to that of LPG. The combustor feeding with biogas produces lower temperatures, both in terms of peak flame temperature and averaged reaction zone temperature. An $84 \%$ of reduction in NOx and a $60 \%$ of reduction in $\mathrm{CO}$ can be achieved compared to the cases burning LPG.

\section{Acknowledgments}

The authors acknowledge the funding by INNOVATE UK, as part of the Energy Catalyst Programme. The technical advice provided by Dr. Vishal Sethi and Dr. Xiaoxiao Sun at Cranfield University are greatly appreciated.

\section{References}

[1]Zornek T, Monz T, Aigner M. "Performance analysis of the micro gas turbine Turbec T100 with a new FLOX-combustion system for low calorific fuels". Applied Energy, Vol. 159, 2015, pp. 276-284.

[2] Pilavachi P A. "Power generation with gas turbine systems and combined heat and power", Applied Thermal Engineering, Vol. 20, No.15-16, 2000, pp. 1421-1429.

[3]De Paepe W, Montero Carrero M, Bram S, et al. "Toward Higher Micro Gas Turbine Efficiency and FlexibilityHumidified Micro Gas Turbines: A Review”. Journal of Engineering for Gas Turbines and Power, Vol.140, No.8, 2018.

[4] Gharehpetian G.B. and Mohammad Mousavi Agah S., Distributed generation systems: design, operation and grid integration. Butterworth-Heinemann, 2017, Chap 4.

[5] Visser, W.P.J., Shakariyants, S., De Later, M.T.L., Haj Ayed, A. and Kusterer, K., 2012, June. Performance optimization of a $3 \mathrm{KW}$ microturbine for CHP applications. In ASME Turbo Expo 2012: Turbine Technical Conference and Exposition (pp. 619-628).

[6] Bladon jet MGT combustor: http://www.gasturbineworld.co.uk/bladon.html (accessed on 11/11/2019)

[7] Liu, C.R. and Shih, H.Y., The Design and Model Simulation of a Micro Gas Turbine Combustor Supplied With Methane/Syngas Fuels. In ASME Turbo Expo 2016: Turbomachinery Technical Conference and Exposition.

[8] Hasemann, S., Seliger, H., Kutne, P. and Aigner, M., 2018, June. Experimental and Numerical Design Study for a Small Scale Jet-Stabilized Micro Gas Turbine Combustor. In ASME Turbo Expo 2018: Turbomachinery Technical Conference and Exposition. American Society of Mechanical Engineers Digital Collection.

[9] Xing, F., Kumar, A., Huang, Y., Chan, S., Ruan, C., Gu, S. and Fan, X. "Flameless combustion with liquid fuel: A review focusing on fundamentals and gas turbine application”. Applied Energy, vol. 193, 2017, pp.28-51.

[10] Fuchs, F., Meidinger, V,. Nicolas, N., Thorsten Reiter, Zündel, M., Challenges in designing very small jet engines - fuel distribution and atomization. 16th International Symposium on Transport Phenomena and Dynamics of Rotating Machinery, Apr 2016, Honolulu, United States.

[11] Olivier, A.J.,. An experimental and numerical investigation of vaporizer tubes associated with micro gas turbines, Doctoral dissertation, Stellenbosch: Stellenbosch University, 2015 (unpublished)

[12] Liedtke, O., Schulz, A. and Wittig, S., January. Design study of a lean premixed prevaporized counter flow combustor for a micro gas turbine. In ASME Turbo Expo 2002: Power for Land, Sea, and Air (pp. 405-412).

[13] Delanaye, M, Giraldo, A, Nacereddine, R, Rouabah, M, Fortunato, V, \& Parente, A. "Development of a Recuperated Flameless Combustor for an Inverted Brayton Cycle Microturbine Used in Residential Micro-CHP." Proceedings of the ASME Turbo Expo 2017: Turbomachinery Technical Conference and Exposition. Volume 4B: Combustion, Fuels and Emissions. Charlotte, North Carolina, USA. June 26-30, 2017.

[14] Tuttle, S, Hinnant, K, \& Vick, M. "Preliminary Design, Ignition, and Fuel Injection for a High Temperature Recuperated Microturbine Combustor." Proceedings of the ASME Turbo Expo 2017: Turbomachinery Technical Conference and Exposition. Volume 4A: Combustion, Fuels and Emissions. Charlotte, North Carolina, USA. June 26-30, 2017.

[15]Sallevelt, J.L.H.P., Gudde, J.E., P., Pozarlik , A,K ., and Brem,G., "The impact of spray quality on the combustion of a viscous biofuel in a micro gas turbine, " Applied Energy, vol. 132,2014, pp.575-585 
[16] Chiong,M.C., Chong, C. T., Ng. J-H, Lam,S.S, Tran, MV.,Chong,W.W, Mohd Jaafar,M,N, and Valera-Medina,A "liquid biofuels production and emissions performance in gas turbines: A review," Energy Conversion and Management, vol. 173,2018, pp.640-658.

[17] Monyem A, H. Van Gerpen J, "The effect of biodiesel oxidation on engine performance and emissions." Biomass Bioenergy, vol 20, 2001, pp. 317-325

[18] Sorate, K A, and Bhale P. V. "Biodiesel properties and automotive system compatibility issues" Renewable and Sustainable Energy Reviews, vol.41,2015, pp.777-798

[19] Díaz-Ballote, L, López-Sansores, J.F. Maldonado-López, L. Garfias-Mesias, L.F. "Corrosion behavior of aluminum exposed to a biodiesel", Electrochemistry Communications, vol. 11, 2009, pp. 41-44

[20] Material safety data sheet (MSDS) Liquefied petroleum gas and propane, version 2, Oct 2018.

[21] Lefebvre, A.H. and Ballal, D.R., Gas turbine combustion: alternative fuels and emissions. CRC press, 2010.

[22] Mellor, A.M., Design of Modern Gas Turbine Combustors, Academic Press, San Diego, CA, 1999.

[23] Saravanamuttoo H I H,Rogers G F C, Cohen H, Gas turbine Theory, Pearson Education, 2001

[24] Material safety data sheet (MSDS) Liquefied petroleum gas and propane, version 2, Oct 2018.

[25] Eric M Goodger, Transport fuelling update on alternatives. Landfall press, 2016

[26] Goodger, E.M. and Ogaji, S.O.,Fuels \& Combustion in heat engines. Cranfield University Press, 2011.

[27] ANSYS Fluent Theory Guide, Release 19.1, ANSYS Inc.

[28] ANSYS Fluent User's Guide, Release 19.1, ANSYS Inc.

[29] Gauthier, PQ. "Comparison of Temperature Fields and Emissions Predictions Using Both an FGM Combustion Model, With Detailed Chemistry, and a Simple Eddy Dissipation Combustion Model with Simple Global Chemistry." Proceedings of the ASME Turbo Expo 2017, Vol.4B, Charlotte, North Carolina, USA, 2017

[30] Tim. C. Lieuwen and Vigor. Yang. Gas turbine emissions, Cambridge University Press, 2013.

[31] De Soete, G.G., "Overall reaction rates of NO and N2 formation from fuel nitrogen." In Symposium (international) on combustion Vol. 15, No. 1, pp. 1093-1102. Elsevier, 1975

[32] Liu, Y., Sun, X., Sethi, V., Nalianda, D., Li, Y.G. and Wang, L., "Review of modern low emissions combustion technologies for aero gas turbine engines." Progress in Aerospace Sciences, Vol.94, 2017, pp.12-45.

[33]Holdeman, J.D, Srinivasan, R, and Berenfeld,A., "Experiments in Dilution Jet Mixing", AIAA Journal,Vol.22,No.10,pp.1436-43,1984.

[34] Fantozzi, F, Laranci, P, Bianchi, M, De Pascale, A, Pinelli, M, \& Cadorin, M. "CFD Simulation of a Microturbine Annular Combustion Chamber Fuelled With Methane and Biomass Pyrolysis Syngas: Preliminary Results." Proceedings of the ASME Turbo Expo 2009: Power for Land, Sea, and Air. Volume 2: Combustion, Fuels and Emissions. Orlando, Florida, USA. June 8-12, 2009. pp. 811-822 
2021-07-28

\section{Combustor development and}

\section{performance analysis for recuperated microturbine application}

Liu, Yize

AIAA

Liu Y, Nikolaidis T, Gamil A, et al., (2021) Combustor development and performance analysis for recuperated microturbine application. In: AIAA Propulsion and Energy 2021 Forum, 9-11 August 2021, Virtual Event https://doi.org/10.2514/6.2021-3637

Downloaded from Cranfield Library Services E-Repository 